\title{
Carryover de herbicidas utilizados no controle de soqueiras do algodoeiro sobre o milho cultivado em sucessão
}

\author{
Carryover of herbicides used in cotton stalk control on corn cultivated in succession
}

\author{
Alessandra Constantin Francischini ${ }^{1}$, Jamil Constantin ${ }^{2}$, Willian Daróz Matte ${ }^{2 \star}$, Rubem Silvério de \\ Oliveira $\mathrm{Jr}^{2}{ }^{2}$, Jonas Rodrigo Henckes ${ }^{2}$
}

${ }^{1}$ Sumitomo Chemical SCLA, São Paulo, SP, Brasil.

${ }^{2}$ Universidade Estadual de Maringá, Maringá, PR, Brasil. *Autor para correspondência: willianmatte@hotmail.com

Submissão: 08/07/2019 / Aceite: 22/06/2020

\begin{abstract}
RESUMO
São limitadas as informações sobre a atividade residual de herbicidas aplicados no controle das soqueiras do algodoeiro e o seu potencial para afetar o desenvolvimento e a produtividade do milho semeado na safra seguinte. $O$ objetivo desse trabalho foi identificar o efeito carryover promovido pela aplicação única e sequencial de herbicidas utilizados no controle das soqueiras do algodoeiro e estimar o intervalo de segurança entre o manejo químico da soqueira do algodoeiro e a semeadura do milho. Foram conduzidos simultaneamente dois experimentos em casa de vegetação, um para aplicação única e outro para aplicação sequencial dos tratamentos herbicidas. Os experimentos foram instalados em esquema fatorial $15 \times 5$, delineados em blocos casualizados com quatro repetições. $O$ primeiro fator foi composto por tratamentos herbicidas e o segundo fator por cinco épocas de semeadura do milho após a aplicação $(0$, 30, 60, 90 e 120 dias). As parcelas experimentais foram compostas de vasos plásticos com capacidade para $3 \mathrm{dm}^{3}$ preenchidos com solo de textura argilosa (470 g kg${ }^{-1}$ de argila), seco e peneirado. Os herbicidas utilizados foram 2,4-D, glyphosate, saflufenacil, [imazapic+imazapyr], dicamba, fluroxypyr e sulfentrazone. Conclui-se que a aplicação sequencial da maioria dos tratamentos proporcionou um aumento na atividade residual dos herbicidas avaliados. Os tratamentos 2,4-D (1340 g ha $\left.{ }^{-1}\right), 2,4-\mathrm{D}+$ glyphosate $\left(1340+720 \mathrm{~g} \mathrm{ha}^{-1}\right)$ e $2,4-\mathrm{D}+$ glyphosate + saflufenacil $\left(1340+720+105 \mathrm{~g} \mathrm{ha}^{-1}\right)$ apresentaram os menores intervalos de segurança e foram aqueles que apresentaram o menor risco de afetar o milho semeado em sucessão, mesmo em aplicações sequenciais. Contudo, os tratamentos constituídos pela associação com herbicidas de maior atividade residual no solo como o dicamba, fluroxypyr, sulfentrazone e [imazapic+imazapyr], apresentaram maior potencial de carryover para a cultura do milho, sendo observado intervalo de segurança superior a 94 dias após a aplicação sequencial de 2,4D + glyphosate + sulfentrazone.
\end{abstract}

PALAVRAS-CHAVE: atividade residual, intervalo de segurança, fitointoxicação.

\begin{abstract}
Information about the residual activity of herbicides sprayed in the control of cotton stalks and its potential to affect the development and productivity of corn sown in the following crop are limited. The objective of this work was to identify the carryover effect promoted by the single and sequential application of herbicides used in the control of cotton stalks and to estimate the plant-back for corn sowing. Two trials were carried out simultaneously in a greenhouse, one for a single application and one for a sequential application of herbicides treatments. It was used a $15 \times 5$ factorial scheme, in a randomized block design with four replicates. The first factor was composed of herbicide treatments and the second factor of five sowing seasons after the application (0,30,60, 90 and 120 days). The experimental plots were composed of plastic pots with a capacity of $3 \mathrm{dm}^{3}$ filled with loamy soil (470 $\mathrm{g} \mathrm{kg}^{-1}$ clay), dried and sieved. The herbicides sprayed were 2,4-D, glyphosate, saflufenacil, [imazapic + imazapyr], dicamba, fluroxypyr, and sulfentrazone. The sequential application of most treatments provided an increase in the residual activity of the evaluated herbicides. The 2,4-D (1,340 $\left.\mathrm{g} \mathrm{ha}^{-1}\right), 2,4-\mathrm{D}+$ glyphosate $\left(1,340+720 \mathrm{~g} \mathrm{ha}^{-1}\right)$ and 2,4-D + glyphosate + saflufenacil $\left(1,340+720+105 \mathrm{~g} \mathrm{ha}^{-1}\right)$ presented the shortest safety intervals and were those that presented the lowest risk of affecting the corn sown in succession, even in sequential applications. However, the treatments that consisted of association with herbicides with higher residual activity in the soil such as dicamba, fluroxypyr, sulfentrazone and [imazapic + imazapyr], presented higher carryover potential for corn crop, being observed a safety interval greater than 94 days after sequential application of
\end{abstract}


2,4-D + glyphosate + sulfentrazone.

KEYWORDS: residual activity, plant back. fitointoxication.

\section{INTRODUÇÃO}

O cultivo do algodoeiro (Gossypium hirsutum L.) é atividade que desperta grande interesse econômico mundial. A planta do algodoeiro é de aproveitamento completo e oferece variadas utilizações nos segmentos têxteis, oleoquímicos, alimentares, entre outros (BELTRÃO 2006, FREIRE 2007). Esta cultura é atacada por diversos insetos-praga, dentre as quais se destaca o bicudo-do-algodoeiro, Anthonomus grandis Boheman (Coleoptera, Curculionidae), responsável por ocasionar danos severos à produção (SILVA \& RAMALHO 2013). A destruição dos restos culturais é uma prática cultural fundamental visando não só ao controle do bicudo, mas também à interrupção do ciclo de outras pragas e doenças de grande importância na cotonicultura (IZEPPI et al. 2011, BIANCHINI \& BORGES 2013, SILVA et al. 2013).

O método mais tradicional para a destruição da soqueira é o mecânico, principalmente por meio de roçagem e gradagem, promovendo a trituração dos tecidos vegetais, mas com os avanços nas práticas agrícolas visando a conservação dos solos, tornou-se imprescindível a utilização de métodos alternativos, como por exemplo, a aplicação de herbicidas (YANG et al. 2006, RIBEIRO et al. 2015). Contudo, a escolha deste manejo deve considerar a persistência dos herbicidas utilizados.

A persistência de um herbicida pode ser definida como a capacidade que ele tem para manter a integridade de sua molécula e suas características físicas, químicas e biocidas no ambiente através do qual ele é transportado e distribuído após a sua liberação (MARCHESAN et al. 2016). Esta persistência depende de características físico-químicas da molécula, bem como de características inerentes ao solo, como a granulometria, $\mathrm{opH}$, a capacidade tampão, a mineralogia, o teor de matéria orgânica e a atividade microbiana, além das condições climáticas (GONÇALVES et al. 2018).

Herbicidas com atividade residual no solo previnem os fluxos de emergência e o desenvolvimento das plantas daninhas de uma determinada área por certo período de tempo (DAN et al. 2012). Porém, alguns herbicidas podem persistir no solo por período suficiente para causar efeitos negativos no crescimento e desenvolvimento das culturas subsequentes, como por exemplo, o milho quando cultivado em sucessão ao algodão. O efeito tóxico causado pela persistência de herbicidas em cultivos em sucessão é conhecido como carryover, que se caracteriza pela redução do crescimento, da produtividade e da qualidade dos produtos colhidos, os quais já foram relatados em diversas culturas (ARTUZI \& CONTIEIRO 2006, SOLTANI et al. 2011, DAN et al. 2012, GONÇALVES et al. 2018, MATTE et al. 2018, MATTE et al. 2019).

Devido à escassez de informações, o objetivo desse trabalho foi identificar o efeito carryover promovido pela aplicação única e sequencial de herbicidas utilizados no controle das soqueiras do algodoeiro e estimar o intervalo de segurança para a semeadura do milho, cultivado em sucessão.

\section{MATERIAL E MÉTODOS}

Os experimentos foram conduzidos em casa de vegetação durante o período de abril a dezembro de 2014. Foram conduzidos simultaneamente dois experimentos, um para aplicação única (Experimento 1/aplicação A) e outro para aplicação sequencial (Experimento 2/aplicação A/B) dos tratamentos herbicidas. Os experimentos foram instalados em esquema fatorial $15 \times 5$, em delineamento de blocos casualizados com quatro repetições. O primeiro fator avaliado foi o tratamento herbicida (Tabela 1) e o segundo fator foi a época de semeadura do híbrido de milho DKB 350 (0, 30, 60, 90 e 120 dias) após a aplicação A no experimento 1, e após a aplicação $B$ no experimento 2. Os tratamentos herbicidas avaliados foram aqueles considerados os mais eficientes na destruição de soqueiras de algodão Fiber Max 966 LL (FRANCISCHINI et al. 2019).

As parcelas experimentais foram compostas de vasos plásticos com capacidade para $3 \mathrm{dm}^{3}$ preenchidos com solo seco e peneirado. Conforme análise química e física, o solo utilizado apresentava as seguintes características: $\mathrm{pH}$ em $\mathrm{CaCl}_{2}$ de 5,$4 ; 18,7 \mathrm{mmol}_{\mathrm{c}} \mathrm{dm}^{-3} \mathrm{de}^{+}+\mathrm{Al}^{+3} ; 40,3 \mathrm{mg} \mathrm{dm}^{-3}$ de $\mathrm{P} ; 50 \mathrm{mmol}_{\mathrm{c}}$ $\mathrm{dm}^{-3}$ de Ca ${ }^{+2} ; 28,7 \mathrm{mmol}_{\mathrm{C}} \mathrm{dm}^{-3} \mathrm{de} \mathrm{Mg}^{+2} ; 2,4 \mathrm{mmol}_{\mathrm{c}} \mathrm{dm}^{-3}$ de K $\mathrm{K}^{+} ; 0,027 \mathrm{~g} \mathrm{~kg}^{-1}$ de M.O.; $480 \mathrm{~g} \mathrm{~kg}^{-1}$ de areia; $50 \mathrm{~g}$ $\mathrm{kg}^{-1}$ de silte; e $470 \mathrm{~g} \mathrm{~kg}^{-1}$ de argila.

No primeiro experimento, a aplicação única dos tratamentos herbicidas $(A)$ foi realizada no dia 27/05/2014. Na ocasião, o híbrido DKB 350 foi semeado para o período de 0 dias após a aplicação (0 DAA). As semeaduras subsequentes foram realizadas em 28/05/2014 (30 DAA), 27/06/2014 (60 DAA), 27/07/2014 (90 DAA) e 27/08/2014 (120 DAA). Logo após a aplicação dos tratamentos herbicidas, todos os vasos receberam irrigação com lâmina de água de $5 \mathrm{~mm}$. Após a irrigação, os vasos que não foram semeados 
permaneceram sem receber mais nenhuma irrigação até receberem a semeadura das culturas. Os vasos semeados receberam irrigação com lâmina de água diária de $5 \mathrm{~mm}$ até o final do experimento.

Tabela 1. Relação dos tratamentos herbicidas utilizados na avaliação do efeito carryover na cultura do milho após aplicação única (aplicação A) e duas aplicações sequenciais (aplicação A/B).

Table 1. Relationship of the herbicide treatments used in the evaluation of the carryover effect on the corn crop after one spray (application A) and two sequential sprays (application A/B).

\begin{tabular}{ll}
\hline Tratamentos & $\begin{array}{l}\text { Aplicação A e B } \\
\text { Dose }\left(\mathrm{g} \mathrm{ha}^{-1 / 1}\right.\end{array}$ \\
\hline $2,4-\mathrm{D}$ & 1340 \\
$2,4-\mathrm{D}+$ glyphosate & $1340+720$ \\
$2,4-\mathrm{D}+$ saflufenacil & $1340+105$ \\
$2,4-\mathrm{D}+[$ [imazapic+imazapyr] & $1340+105$ \\
$2,4-\mathrm{D}+$ glyphosate + saflufenacil & $1340+720+105$ \\
$2,4-\mathrm{D}+$ glyphosate + [imazapic+imazapyr] & $1340+720+105$ \\
2,4-D + glyphosate + saflufenacil + [imazapic+imazapyr] & $1340+720+105+105$ \\
Glyphosate + saflufenacil + [imazapic+imazapyr] & $720+105+105$ \\
Glyphosate + saflufenacil + fluroxypyr & $720+105+400$ \\
Glyphosate + fluroxypyr + [imazapic+imazapyr] & $720+400+105$ \\
Glyphosate + dicamba + saflufenacil & $720+960+105$ \\
Glyphosate + sulfentrazone + 2,4-D & $720+40+1340$ \\
Sulfentrazone + 2,4-D & $40+1340$ \\
Fluroxypyr & 400 \\
Testemunha sem aplicação & - \\
\hline
\end{tabular}

Todos os tratamentos herbicidas foram aplicados em associação com Dash HC 0,5 \%.

${ }^{/ 1}$ Dose de 2,4-D e glyphosate em e.a. e os demais herbicidas em i.a.

No segundo experimento, o qual apresentava duas aplicações sequenciais (aplicações A/B), a primeira aplicação (A) foi realizada no dia 27/04/2014, e a segunda aplicação (B) foi realizada 45 dias após a primeira (11/06/2014). Após a aplicação $A$, os vasos receberam uma irrigação com lâmina de água de 5 $\mathrm{mm}$ e ficaram sem receber mais nenhuma irrigação por 45 dias até a realização da segunda aplicação (B). Após a segunda aplicação (B) foi realizada nova irrigação com lâmina de água de $5 \mathrm{~mm}$. Os vasos que não receberam a semeadura do milho permaneceram em situação de déficit hídrico até receberem a semeadura da cultura. Os vasos semeados receberam lâmina de água diária de $5 \mathrm{~mm}$ até o final do experimento.

O intervalo de 45 dias entre a primeira e a segunda aplicação foi estipulado simulando o tempo necessário para as soqueiras de algodoeiro rebrotarem no campo e apresentarem área foliar suficiente para a absorção dos tratamentos herbicidas na segunda aplicação (FRANCISCHINI et al. 2019). A ausência de irrigação nos vasos após as aplicações visou simular situação comum nas áreas produtoras de algodão, nas quais ocorrem períodos pronunciados de seca após a colheita, durante o período destinado ao controle das soqueiras do algodoeiro. Assim, para o experimento com duas aplicações sequenciais $(A / B)$ a semeadura do milho foi realizada em 11/06/2014 (0 DAA), 04/07/2014 (30 DAA), 04/08/2014 (60 DAA), 04/09/2014 (90 DAA) e 04/10/2014 (120 DAA).

Em todas as aplicações, foi utilizado um pulverizador costal de pressão constante à base de $\mathrm{CO}_{2}$, equipado com barra munida de três pontas tipo jato leque XR-110.02, espaçadas de $50 \mathrm{~cm}$ entre si, sob pressão de $200 \mathrm{kPa}$. Estas condições de aplicação proporcionaram o equivalente a $150 \mathrm{~L} \mathrm{ha}^{-1}$ de calda. As condições climáticas no momento das aplicações dos tratamentos foram: (A) umidade relativa do ar de 67\%, temperatura de $25,9 \stackrel{\circ}{\circ}$, velocidade do vento de $0,8 \mathrm{~km} \mathrm{~h}^{-1}$ e solo úmido; (B) umidade relativa do ar de $79 \%$, temperatura de $26,8^{\circ} \mathrm{C}$, velocidade do vento de $0,6 \mathrm{~km} \mathrm{~h}^{-1}$ e solo úmido.

Foram realizadas avaliações de fitointoxicação nas plantas de milho aos 14 dias após a semeadura (DAS) por meio de uma escala de 0 a $100 \%$, em que $0 \%$ representa ausência de sintomas, e $100 \%$ representa morte das plantas. Aos 30 DAS, final do experimento, foram avaliados à altura das plantas e a matéria seca da parte aérea. Os dados de matéria seca e altura foram corrigidos para valores percentuais em comparação com a testemunha sem aplicação, partindo-se do princípio de que os vasos que permaneceram sem aplicação de herbicida apresentavam altura e matéria seca relativa de 100\%. 
Os dados de fitointoxicação, altura e massa da matéria seca foram submetidos à análise de variância pelo teste $\mathrm{F}$ e as médias foram comparadas com a testemunha sem aplicação pelo Teste de Dunnett $(\mathrm{p}<0,01)$.

Modelos de regressão não-lineares foram ajustados em função dos intervalos entre as aplicações e a semeadura, para cada tratamento herbicida (Tabela 2). A partir do ajuste, buscou-se estipular o intervalo de segurança (IS) com base nas variáveis-resposta analisadas.

Tabela 2. Modelos de regressão ajustados para estimar o intervalo de segurança para a semeadura da cultura do milho.

Table 2. Adjusted regression models to estimate the safety interval for corn sowing.

Modelos de regressão

Modelo Sigmoidal de Boltzmann (3 parâmetros)

$\hat{Y}=\frac{a}{1+e^{-\left(x-\frac{x y}{y}\right)}}$

Modelo Sigmoidal de Boltzmann (4 parâmetros)

Modelo Logístico de Streibig (3 parâmetros)

$\hat{Y}=y 0+\frac{a-y 0}{1+\theta^{-\left(x-\frac{x y}{b}\right)}}$

$\hat{y}=\frac{a}{\left[1+\left(\frac{x}{x 0}\right)^{2}\right]}$

Modelo Logístico de Streibig (4 parâmetros)

$\hat{P}=y_{0}+\frac{a}{\left[1+\left(\frac{x}{x 0}\right)^{2}\right]}$

Modelo Exponencial (2 parâmetros)

$P=a e^{-5 x}$

Modelo Simétrico (3 parâmetros)

$\hat{P}=a|x-x 0|^{2}$

Em que: ${ }^{\not}=$ altura, biomassa e/ou fitointoxicação; $x=$ dias após a semeadura; $y 0=$ valor mínimo de altura, biomassa e/ou fitointoxicação; a = assíntota máxima da função (valor máximo de altura, biomassa e/ou fitointoxicação); x0 = "dias" que proporcionam $50 \%$ do valor da "a"; $b=$ declividade da curva ao redor de $\mathrm{x} 0$.

Para considerar seguro a semeadura do milho após utilização dos tratamentos herbicidas avaliados, considerou-se como tolerável neste trabalho os seguintes critérios: fitointoxicação - aceitável até 10\%; altura de plantas - redução de no máximo 10\% em relação à altura da testemunha; massa seca relativa - redução de no máximo $10 \%$ em relação à massa seca da testemunha. Ao final, foi eleito como intervalo de segurança o maior valor obtido dentre as três variáveis analisadas.

\section{RESULTADOS E DISCUSSÃO}

Houve interação significativa dos tratamentos herbicidas e da época de semeadura do milho para todas as variáveis analisadas, quando se realizou a aplicação única dos tratamentos. Os resultados de fitointoxicação nas plantas de milho estão apresentados na Tabela 3.

Todos os tratamentos herbicidas aplicados no dia da semeadura (0 DAA) ocasionaram níveis de fitointoxicação superior a $10 \%$ nas plantas de milho. Na semeadura do milho realizada aos 30 dias, os tratamentos 2,4-D, 2,4-D + glyphosate, 2,4-D + saflufenacil, 2,4-D + [imazapic+imazapyr] e 2,4-D + glyphosate + saflufenacil apresentaram fitointoxicação visual das plantas de milho inferior a $1,7 \%$, não diferindo da testemunha sem aplicação. A aplicação de glyphosate + dicamba + saflufenacil proporcionou a maior fitointoxicação visual $(58,5 \%)$ nas plantas de milho, quando semeado aos 30 dias.

Para o milho semeado aos $60 \mathrm{DAA}$, além dos tratamentos anteriormente citados, a aplicação de 2,4D + glyphosate + [imazapic+imazapyr] e glyphosate + saflufenacil + [imazapic+imazapyr] resultou em baixos níveis de fitointoxicação $(<2,5 \%)$ nas plantas e não diferiu da testemunha sem aplicação. Nas semeaduras realizadas aos 90 e 120 DAA, nenhum dos tratamentos proporcionou níveis significativos de fitointoxicação, não sendo observadas diferenças entre os tratamentos herbicidas e a testemunha sem aplicação.

No presente trabalho, os principais sintomas observados com a aplicação de 2,4-D foram epinastia das folhas e da haste das plantas de milho. GOMES et al. (2017) também evidenciaram a atividade residual de 2,4-D (698 g e.a. ha ${ }^{-1}$ ), aplicado isolado ou em mistura com glyphosate, sobre o milho semeado até 10 dias após a aplicação. Segundo os autores, níveis de fitointoxicação superiores a $20 \%$ foram observados quando o milho foi semeado cinco dias após a aplicação. 
Tabela 3. Fitointoxicação do milho semeado aos 0, 30, 60, 90 e 120 dias após a aplicação dos tratamentos herbicidas. Experimento 1.

Table 3. Phytointoxication of corn sown at 0, 30, 60, 90, and 120 days after application of herbicide treatments. Experiment 1.

\begin{tabular}{|c|c|c|c|c|c|c|c|c|c|}
\hline \multirow{2}{*}{ Tratamentos (Aplicação A) } & \multicolumn{9}{|c|}{ Fitointoxicação (\%) aos 14 DAS } \\
\hline & 0 Dias & $\mathrm{S} \quad 30 \mathrm{D}$ & & $60 \mathrm{D}$ & & $90 \mathrm{Di}$ & & $120 \mathrm{Dia}$ & \\
\hline 2,4-D & 23,0 & 1,2 & + & 0,0 & + & 0,0 & + & $0,0+$ & \\
\hline 2,4-D + glyphosate & 25,0 & 1,5 & + & 0,0 & + & 0,0 & + & 0,0 & \\
\hline $2,4-D+$ saflufenacil & 15,5 & 0,0 & + & 0,0 & + & 0,0 & + & 0,0 & \\
\hline 2,4-D + [imazapic+imazapyr] & 13,5 & 0,0 & + & 0,0 & + & 0,0 & + & 0,0 & \\
\hline 2,4-D + glyphosate + saflufenacil & 12,5 & 1,7 & + & 0,0 & + & 0,0 & + & 0,0 & + \\
\hline 2,4-D + glyphosate + [imazapic + imazapyr] & 19,0 & 7,0 & - & 2,5 & + & 0,0 & + & 0,0 & + \\
\hline 2,4-D + glyphosate + saflufenacil + [imazapic+imazapyr] & 84,0 & 46,2 & - & 4,0 & - & 0,0 & + & 0,0 & \\
\hline 2,4-D + glyphosate + sulfentrazone & 47,7 & 32,7 & - & 17,2 & - & 3,0 & + & 0,0 & + \\
\hline 2,4-D + sulfentrazone & 37,7 & 28,2 & - & 4,7 & - & 0,7 & + & 0,0 & + \\
\hline Glyphosate + saflufenacil + fluroxypyr & 33,5 & 23,0 & - & 4,5 & - & 0,0 & + & 0,0 & + \\
\hline Glyphosate + [imazapic+imazapyr] + fluroxypyr & 41,7 & 22,5 & - & 3,7 & - & 0,0 & + & 0,0 & + \\
\hline Glyphosate + dicamba + saflufenacil & 83,5 & 58,5 & - & 14,5 & - & 2,2 & + & 0,0 & + \\
\hline Glyphosate + saflufenacil + [imazapic+imazapyr] & 21,7 & 12,7 & - & 2,2 & + & 0,0 & + & 0,0 & + \\
\hline Fluroxypyr & 48,2 & 22,5 & - & 15,2 & - & 3,0 & + & 0,0 & + \\
\hline Testemunha sem aplicação & 0,0 & 0,0 & + & 0,0 & + & 0,0 & + & 0,0 & + \\
\hline $\mathrm{CV} \%$ & 7,4 & 12,2 & & 27,3 & & 26,5 & & 0,0 & \\
\hline DMS & 5,2 & 4,3 & & 2,6 & & 4,2 & & 0,0 & \\
\hline
\end{tabular}

DAS = dias após a semeadura; Sinais "+" indicam semelhança entre o tratamento e a testemunha pelo teste de Dunnet $(\mathrm{p} \leq 0,01)$.

A maior parte dos tratamentos utilizados na destruição das soqueiras do algodoeiro afetou a altura das plantas de milho quando a semeadura foi realizada até 60 dias (Tabela 4). A aplicação de 2,4-D foi o único tratamento que não afetou o crescimento do milho em nenhuma data de semeadura. Os tratamentos 2,4-D + glyphosate + saflufenacil + [imazapic+imazapyr] e glyphosate + dicamba + saflufenacil foram os que promoveram as menores alturas de plantas em relação à testemunha sem aplicação.

Tabela 4. Altura relativa (porcentagem em relação à testemunha sem herbicida) das plantas de milho semeadas aos 0, 30, 60, 90 e 120 dias após uma aplicação dos tratamentos herbicidas. Experimento 1.

Table 4. Relative height (relative percentage of a check without herbicide) of corn plants sown at 0, 30, 60, 90 and 120 days after an application of the herbicide treatments. Experiment 1.

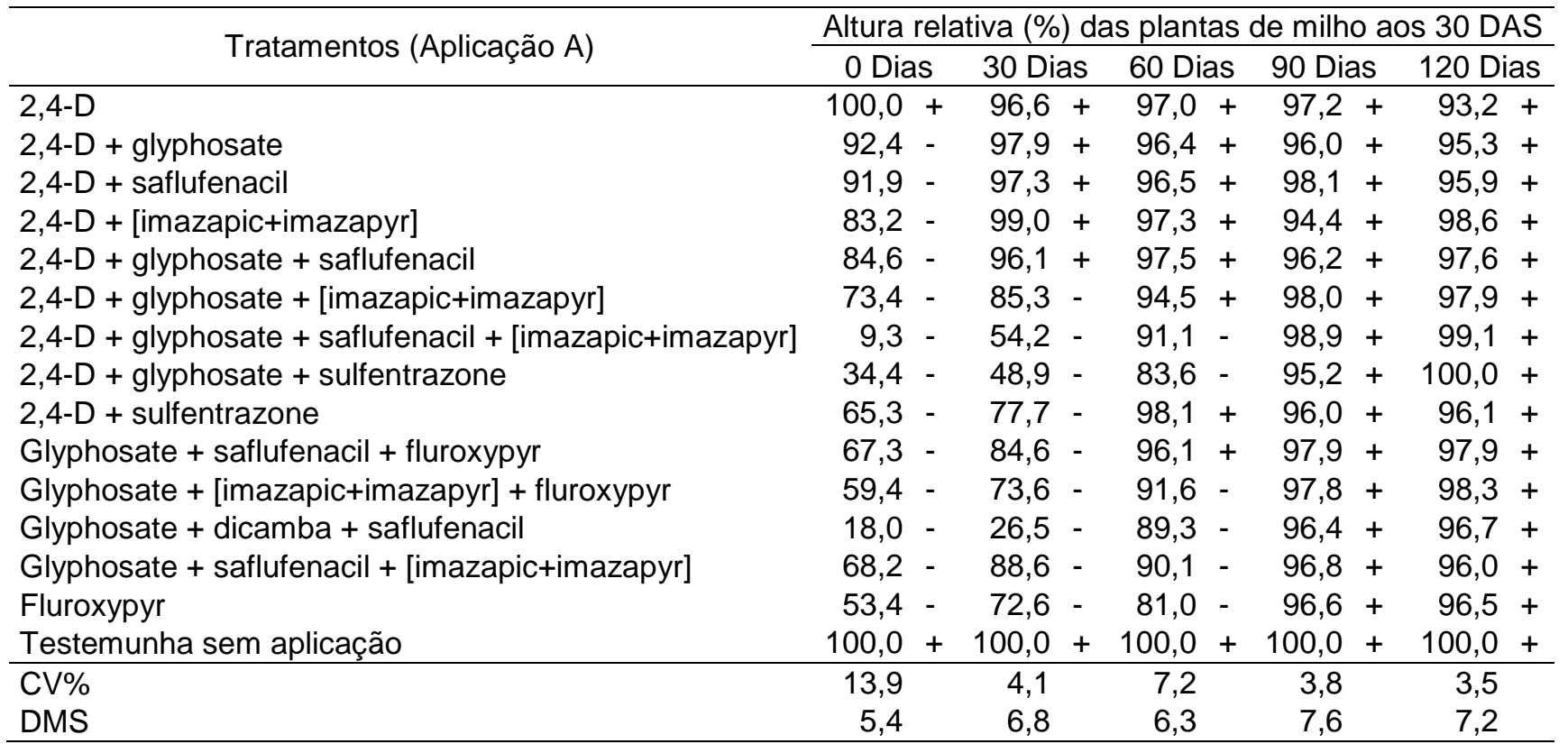

DAS = dias após a semeadura; Sinais "+" indicam semelhança entre o tratamento e a testemunha pelo teste de Dunnet $(p \leq 0,01)$. 
Na semeadura realizada aos 30 dias, além do 2,4-D, os tratamentos 2,4-D + glyphosate, 2,4-D + [imazapic+imazapyr] e 2,4-D + saflufenacil também não afetaram significativamente a altura das plantas de milho. Os tratamentos 2,4-D + glyphosate +[imazapic+imazapyr], 2,4-D + glyphosate + sulfentrazone e glyphosate + saflufenacil + fluroxypyr só apresentaram altura das plantas de milho semelhante à testemunha quando o milho foi semeado aos 60 dias. Nas semeaduras de 90 e 120 dias não observou-se efeito dos tratamentos herbicidas sobre a altura das plantas de milho.

A aplicação dos tratamentos herbicidas reduziu a massa seca das plantas, principalmente quando a semeadura do milho ocorreu em um intervalo de até 60 dias (Tabela 5). Os tratamentos 2,4-D e 2,4-D + glyphosate não afetaram a massa seca das plantas de milho em nenhuma das épocas de semeadura. Excluindo os tratamentos citados, houve redução de massa da matéria seca das plantas de milho para todos os demais tratamentos na semeadura realizada no dia da aplicação (0 DAA). Os tratamentos que mais reduziram a massa seca foram 2,4-D + glyphosate + saflufenacil + [imazapic+imazapyr] e glyphosate + dicamba + saflufenacil, apresentando massa seca relativa em relação à testemunha de 35,3 e 33,9\%, respectivamente.

Tabela 5. Massa seca relativa (porcentagem em relação à testemunha sem herbicida) das plantas de milho semeadas aos 0, 30, 60, 90 e 120 dias após uma aplicação dos tratamentos herbicidas. Experimento 1.

Table 5. Relative dry mass (relative percentage of a check without herbicide) of maize plants sown at 0, 30, 60, 90 and 120 days after application of herbicide treatments. Experiment 1.

\begin{tabular}{|c|c|c|c|c|c|c|c|}
\hline \multirow{2}{*}{ Tratamentos (Aplicação A) } & \multicolumn{7}{|c|}{ Massa seca relativa (\%) do milho aos 30 DAS } \\
\hline & 0 Dias & $30 \mathrm{Dia}$ & as $60 \mathrm{Dia}$ & as $90 \mathrm{Dia}$ & & $120 \mathrm{D}$ & \\
\hline $2,4-\mathrm{D}$ & $96,3+$ & 96,4 & 99,2 & 98,6 & + & 97,8 & + \\
\hline 2,4-D + glyphosate & $98,8+$ & 97,7 & 98,3 & 95,9 & + & 95,3 & + \\
\hline $2,4-D+$ saflufenacil & $88,4-$ & 97,1 & 96,5 & 98,9 & + & 97,5 & + \\
\hline 2,4-D + [imazapic+imazapyr] & $79,1-$ & 91,2 & 98,2 & 96,9 & + & 97,6 & + \\
\hline 2,4-D + glyphosate + saflufenacil & $80,9-$ & 92,5 & 96,0 & 96,2 & + & 97,0 & + \\
\hline 2,4-D + glyphosate + [imazapic+imazapyr] & $69,9-$ & 92,0 & 97,4 & 97,5 & + & 98,6 & + \\
\hline 2,4-D + glyphosate + saflufenacil + [imazapic+imazapyr] & $35,3-$ & 71,5 & 92,3 & 97,9 & + & 96,6 & + \\
\hline 2,4-D + glyphosate + sulfentrazone & $46,7-$ & 55,0 & 84,6 & 99,3 & + & 97,4 & + \\
\hline 2,4-D + sulfentrazone & $57,2-$ & 83,4 & 99,6 & 98,0 & + & 98,6 & + \\
\hline Glyphosate + saflufenacil + fluroxypyr & $71,4-$ & 83,7 & 99,4 & 98,0 & + & 97,9 & + \\
\hline Glyphosate + [imazapic+imazapyr] + fluroxypyr & $50,2-$ & 76,6 & 91,8 & 97,6 & + & 98,5 & + \\
\hline Glyphosate + dicamba + saflufenacil & 33,9 & 52,5 & 91,8 & 100,0 & + & 97,9 & + \\
\hline Glyphosate + saflufenacil + [imazapic+imazapyr] & $74,0-$ & 82,6 & 85,6 & 98,9 & + & 99,9 & + \\
\hline Fluroxypyr & 56,9 & 71,4 & 75,9 & 99,4 & + & 98,1 & + \\
\hline Testemunha sem aplicação & $100,0+$ & $+100,0$ & $+100,0$ & $+100,0$ & + & 100,0 & + \\
\hline CV\% & 4,8 & 3,5 & 4,3 & 6,9 & & 3,1 & \\
\hline DMS & 6,9 & 6,0 & 4,5 & 6,0 & & 6,3 & \\
\hline
\end{tabular}

DAS = dias após a semeadura; Sinais “+" indicam semelhança entre o tratamento e a testemunha pelo teste de Dunnet $(p \leq 0,01)$.

Para a semeadura aos 30 dias, as plantas de milho tratadas com 2,4-D + saflufenacil também apresentaram massa seca semelhante à testemunha sem herbicida. Os tratamentos 2,4-D + glyphosate + saflufenacil + [imazapic+imazapyr], 2,4-D + sulfentrazone, glyphosate + [imazapic+imazapyr] + fluroxypyr, glyphosate + dicamba + saflufenacil, glyphosate + saflufenacil + [imazapic+imazapyr] e fluroxypyr proporcionaram menores valores de massa seca das plantas de milho até 60 dias. Quando o milho foi semeado aos 90 e 120 dias, não foram mais observadas diferenças nos valores de massa seca das plantas.

O IS foi estimado após a aplicação única dos tratamentos herbicidas com base nos dados obtidos e nas tolerâncias máximas propostas neste trabalho (10\% de redução em relação à testemunha sem herbicida). As curvas ajustadas estão apresentadas na Figura 1, as equações utilizadas nas regressões na Tabela 6 e o IS na Tabela 7.

Os tratamentos 2,4-D + saflufenacil, 2,4-D e 2,4-D + glyphosate apresentaram os menores intervalos de segurança para a semeadura do milho após a aplicação única visando ao manejo das soqueiras do algodoeiro, 2, 8 e 9 dias, respectivamente. Por outro lado, os tratamentos com fluroxypyr (82 dias), 2,4-D + glyphosate + sulfentrazone (79 dias) e glyphosate + dicamba + saflufenacil (67 dias), apresentaram os maiores valores de IS e potencial de carryover caso o milho seja semeado em períodos inferiores aos citados. 
Tabela 6. Equações ajustadas para estimar o intervalo de segurança visando à semeadura do milho após a aplicação única de herbicidas no controle de soqueiras do algodoeiro. Experimento 1.

Table 6. Equations adjusted to estimate the safety interval for maize sowing after the single application of herbicides in the cotton stalks control. Experiment 1.

\begin{tabular}{|c|c|c|c|}
\hline Tratamentos & Fitointoxicação & Altura relativa & Matéria seca relativa \\
\hline 2,4-D & $\hat{y}=23.00^{*} E X P\left(-0.09^{*} x\right)$ & - & - \\
\hline 2,4-D + glyphosate & $\hat{Y}=25.00^{*} E X P\left(-0.09^{*} x\right)$ & \multirow{13}{*}{\begin{tabular}{l}
\multicolumn{1}{c}{-} \\
$\hat{y}=97.36 /(1+E X P(-$ \\
$(X+2.62) / 1.47))$ \\
$\hat{y}=97.17 /(1+E X P(-$ \\
$(X+21.09) / 11.06))$ \\
$\hat{y}=100.08 /(1+E X P(-$ \\
$(X+35.33) / 35.45))$ \\
$\hat{y}=101.05 /(1+E X P(-(x-$ \\
$28.58) / 3.03))$ \\
$\hat{y}=106.76 /(1+E X P(-(x-$ \\
$27.69) / 30.58))$ \\
$\hat{y}=99.21 /(1+E X P(-$ \\
$(x+18.07) / 30.27))$ \\
$\hat{y}=99.40 /(1+E X P(-$ \\
$(x+19.52) / 26.82))$ \\
$\hat{y}=103.09 /(1+E X P(-$ \\
$(x+9.87) / 37.34))$ \\
$\hat{y}=98.50 /(1+E X P(-(x-$ \\
$38.93) / 11.33))$ \\
$\hat{\vec{p}}=95.75 /(1+E X P(-$ \\
$(x+19.97) / 21.58))$ \\
$\hat{\vec{y}}=103.28 /(1+E X P(-$ \\
$(x+3.54) / 42.30))$
\end{tabular}} & \multirow{13}{*}{\begin{tabular}{l}
\multicolumn{1}{c}{-} \\
$\hat{y}=97.77 /(1+E X P(-$ \\
$(x+26.51) / 11.79))$ \\
$\hat{y}=98.13 /(1+E X P(-$ \\
$(x+32.55) / 22.95))$ \\
$\hat{P}=96.88 /(1+E X P(-$ \\
$(x+33.77) / 20.77))$ \\
$\hat{y}=98.29 /(1+E X P(-$ \\
$(x+15.03) / 16.67))$ \\
$\hat{y}=98.32 /(1+E X P(-(x-$ \\
$11.03) / 18.72))$ \\
$\hat{y}=108.91 /(1+E X P(-(x-$ \\
$17.48) / 38.98))$ \\
$\hat{y}=99.00 /(1+E X P(-$ \\
$(x+5.60) / 20.38))$ \\
$\hat{y}=100.35 /(1+E X P(-$ \\
$(x+25.60) / 29.67))$ \\
$\hat{y}=99.81 /(1+E X P(-$ \\
$(x+0.17) / 25))$ \\
$\hat{y}=103.8 /(1+E X P(-(x-$ \\
$22.32) / 24.2))$ \\
$\hat{P}=129.91 /(1+E X P(-$ \\
$(x+34.90) / 123.80))$ \\
$\hat{y}=120.14 /(1+E X P(-(x-$ \\
$7.63) / 68.10))$
\end{tabular}} \\
\hline 2,4-D + saflufenacil & $\hat{y}=15.508^{*} E X P\left(-0.26^{*} x\right)$ & & \\
\hline 2,4-D + [imazapic+imazapyr] & $\hat{\gamma}=13.50^{\star} E X P(-0.26 x)$ & & \\
\hline 2,4-D + glyphosate + saflufenacil & $\hat{Y}=12.50^{*} E X P\left(-0.06^{*} X\right)$ & & \\
\hline $\begin{array}{l}\text { 2,4-D + glyphosate } \\
+[\text { imazapic+imazapyr] }\end{array}$ & $\hat{\mathrm{Y}}=18.99 /\left(1+\left((x / 24.32)^{\wedge} 2.46\right)\right)$ & & \\
\hline $\begin{array}{l}\text { 2,4-D + glyphosate + saflufenacil } \\
+ \text { [imazapic+imazapyr] }\end{array}$ & $\hat{\gamma}=83.99 /\left(1+\left((x / 31.33)^{\wedge} 4.68\right)\right)$ & & \\
\hline $\begin{array}{l}\text { 2,4-D + glyphosate + } \\
\text { sulfentrazone }\end{array}$ & $\hat{y}=47.16 /\left(1+\left((x / 43.09)^{\wedge} 2.71\right)\right)$ & & \\
\hline 2,4-D + sulfentrazone & $\hat{y}=38.46 /\left(1+\left((x / 37.74)^{\wedge} 4.39\right)\right)$ & & \\
\hline $\begin{array}{l}\text { Glyphosate + saflufenacil + } \\
\text { fluroxypyr }\end{array}$ & $\hat{y}=33.46 /\left(1+\left((x / 36.64)^{\wedge} 3.98\right)\right)$ & & \\
\hline $\begin{array}{l}\text { Glyphosate + } \\
\text { [imazapic+imazapyr] + fluroxypyr }\end{array}$ & $\hat{Y}=41.73 /\left(1+\left((x / 31.31)^{\wedge} 3.73\right)\right)$ & & \\
\hline $\begin{array}{l}\text { Glyphosate + dicamba + } \\
\text { saflufenacil }\end{array}$ & $\hat{\gamma}=83.39 /\left(1+\left((x / 38.14)^{\wedge} 3.61\right)\right)$ & & \\
\hline $\begin{array}{l}\text { Glyphosate + saflufenacil + } \\
\text { [imazapic+imazapyr] }\end{array}$ & $\hat{y}=21.74 /\left(1+\left((x / 32.94)^{\wedge} 3.78\right)\right)$ & & \\
\hline Fluroxypyr & $\hat{\mathrm{P}}=48.06 /\left(1+\left((x / 29.89)^{\wedge} 1.86\right)\right)$ & & \\
\hline Testemunha sem aplicação & - & - & - \\
\hline
\end{tabular}

(-) não ajustada; Em que: $\hat{P}_{=}$altura, biomassa e/ou fitointoxicação; $x=$ dias após a semeadura.

Tabela 7. Intervalo de segurança estimado com base nos dados de fitointoxicação, altura relativa e massa seca relativa após uma única aplicação dos tratamentos herbicidas visando à semeadura do milho. Experimento 1.

Table 7. Estimated safety interval based on phytotoxicity data, relative height and relative dry mass after a single application of herbicide treatments for maize sowing. Experiment 1.

Tratamentos (Aplicação A)

Intervalo de Segurança (IS) para o milho (em dias após a aplicação) $)^{1 /}$

\begin{tabular}{|c|c|c|c|}
\hline & Fitointoxicação & Altura & Massa seca \\
\hline $2,4-\mathrm{D}$ & 8 & 0 & 0 \\
\hline 2,4-D + glyphosate & 9 & 0 & 0 \\
\hline 2,4-D + saflufenacil & 1 & 0 & 2 \\
\hline 2,4-D + [imazapic+imazapyr] & 1 & 1 & 22 \\
\hline 2,4-D + glyphosate + saflufenacil & 3 & 6 & 19 \\
\hline 2,4-D + glyphosate +[imazapic+imazapyr] & 22 & 41 & 24 \\
\hline 2,4-D + glyphosate + saflufenacil + [imazapic+imazapyr] & 47 & 57 & 55 \\
\hline 2,4-D + glyphosate + sulfentrazone & 73 & 79 & 77 \\
\hline $2,4-\mathrm{D}+$ sulfentrazone & 48 & 51 & 39 \\
\hline Glyphosate + saflufenacil + fluroxypyr & 45 & 41 & 38 \\
\hline Glyphosate + [imazapic+imazapyr] + fluroxypyr & 42 & 61 & 54 \\
\hline Glyphosate + dicamba + saflufenacil & 66 & 65 & 67 \\
\hline Glyphosate + saflufenacil + [imazapic+imazapyr] & 34 & 39 & 65 \\
\hline Fluroxypyr & 63 & 76 & 82 \\
\hline Testemunha sem aplicação & - & - & - \\
\hline
\end{tabular}

Rev. Ciênc. Agrovet., Lages, SC, Brasil (ISSN 2238-1171) 
a)

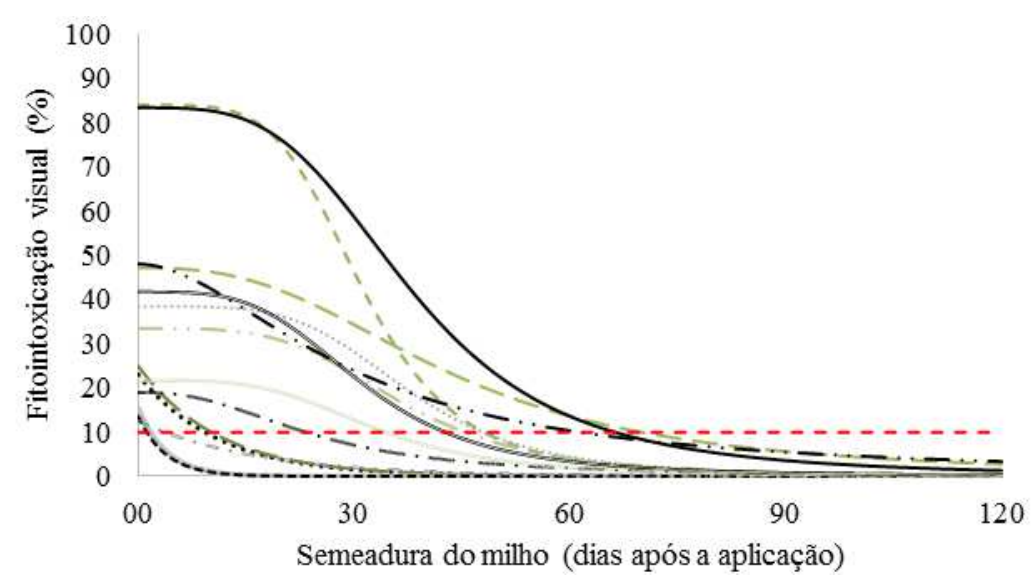

b)

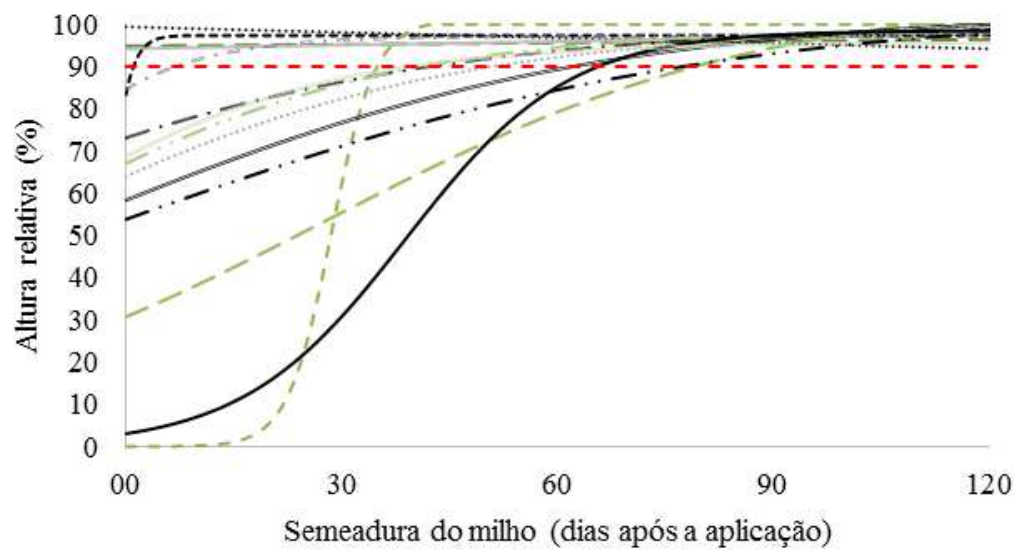

c)

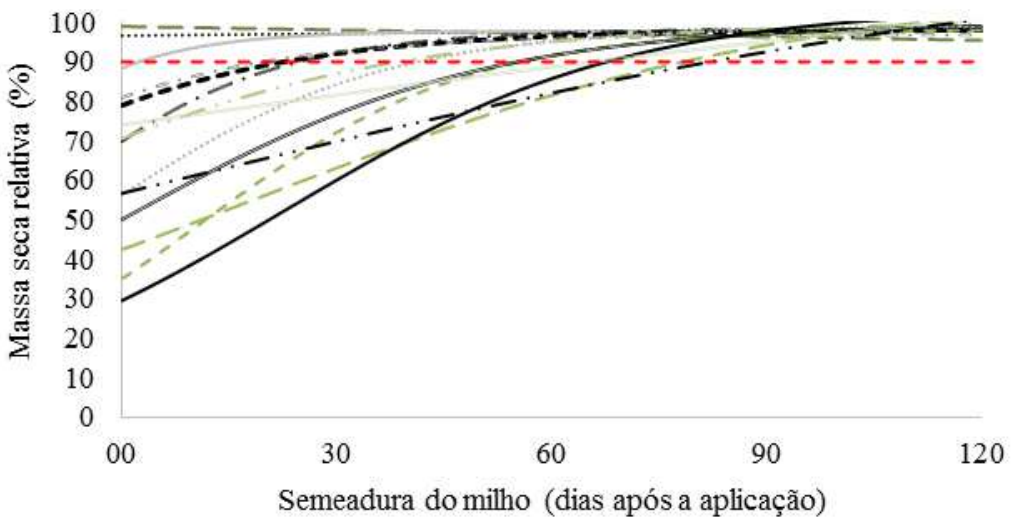

\begin{tabular}{|c|c|}
\hline ............ 2,4-D & $---2,4-D+$ glyphosate \\
\hline 2,4-D + saflufenacil & $----2,4-D+[$ imazapictimazapyr $]$ \\
\hline$-\cdots-2,4-D+$ glyphosate + sflufenacil & - - 2,4-D + glyphosate $+[$ imazapic +imazapy $]$ \\
\hline$----2,4-D+$ glyphosate + sfflufenacil + [im az apictimaz apyr] & $---2,4-D+$ glyphosate + sulfentraz one \\
\hline$\ldots \ldots \ldots \ldots . \cdots 2,4-D+$ sulfentrazone & - - - Glyphosate + saflufenacil + fluroxypyr \\
\hline$\longrightarrow$ Glyphosate + [im az apic+im az apyr $]+$ flur oxypyr & - Glyphosate + dicamba + saflufenacil \\
\hline Glyphosate + saflufenacil + [im azapictimazapyr $]$ & - - - Fluroxypyr \\
\hline
\end{tabular}

Figura 1. Fitointoxicação (a), altura relativa (b) e massa seca relativa (c) das plantas de milho semeadas aos 0, 30, 60, 90 e 120 dias após a aplicação única dos tratamentos herbicidas utilizados no controle de soqueiras do algodoeiro. Experimento 1.

Figure 1. Phytointoxication (a), relative height (b) and relative dry mass (c) of corn plants sown at 0, 30, 60, 90 and 120 days after the single application of the herbicide treatments used to control cotton stalks. Experiment 1. 
Houve interação significativa dos tratamentos herbicidas e da época de semeadura do milho quando foram realizadas duas aplicações sequenciais dos tratamentos (A/B). Os resultados de fitointoxicação estão apresentados na Tabela 8.

Tabela 8. Fitointoxicação do milho semeado aos 0, 30, 60, 90 e 120 dias após duas aplicações sequenciais dos tratamentos herbicidas. Experimento 2.

Table 8. Corn phytotoxification seeded at 0,30,60,90 and 120 days after two sequential applications of the herbicide treatments. Experiment 2.

\begin{tabular}{|c|c|c|c|c|c|c|c|}
\hline \multirow{2}{*}{ Tratamentos (Aplicação A/B) } & \multicolumn{7}{|c|}{ Fitointoxicação (\%) das plantas de milho aos 14 DAS } \\
\hline & 0 Dias & 30 Dias & 60 Dias & s 90 Dias & & 120 Dias & \\
\hline 2,4-D & 23,0 & 2,7 & 0,0 & $+\quad 0,0$ & + & 0,0 & \\
\hline 2,4-D + glyphosate & 16,5 & 2,5 & 0,0 & 0,0 & + & 0,0 & + \\
\hline 2,4-D + saflufenacil & 14,7 & 2,5 & 0,0 & 0,0 & + & 0,2 & + \\
\hline 2,4-D + [imazapic+imazapyr] & 36,7 & 22,7 & 1,2 & 0,2 & + & 0,0 & + \\
\hline 2,4-D + glyphosate + saflufenacil & 38,2 & 32,7 & 2,5 & 0,0 & + & 0,0 & + \\
\hline 2,4-D + glyphosate + [imazapic+imazapyr] & 82,7 & 51,2 & 20,7 & 0,0 & + & 0,0 & + \\
\hline 2,4-D + glyphosate + saflufenacil + [imazapic+imazapyr] & 65,0 & 38,7 & 17,0 & 0,2 & + & 0,0 & + \\
\hline 2,4-D + glyphosate + sulfentrazone & 77,0 & 56,5 & 33,2 & 9,7 & - & 0,5 & + \\
\hline 2,4-D + sulfentrazone & 65,0 & 40,5 & 14,0 & 0,0 & + & 0,0 & + \\
\hline Glyphosate + saflufenacil & 51,0 & 13,0 & 1,2 & 0,2 & + & 0,0 & + \\
\hline Glyphosate + [imazapic+imazapyr] + fluroxypyr & 52,0 & 40,0 & 16,5 & 0,7 & + & 0,0 & + \\
\hline Glyphosate + dicamba + saflufenacil & 100,0 & 78,2 & 24,7 & 1,2 & + & 0,5 & + \\
\hline Glyphosate + saflufenacil + [imazapic+imazapyr] & 62,5 & 38,0 & 21,2 & 2,2 & - & 0,0 & + \\
\hline Fluroxypyr & 67,0 & 41,2 & 13,0 & 4,2 & - & 0,5 & + \\
\hline Testemunha sem aplicação & 0,0 & 0,0 & 0,0 & 0,0 & + & 0,0 & + \\
\hline CV\% & 6,1 & 8,0 & 14,0 & 54,7 & & 17,4 & \\
\hline DMS & 6,4 & 5,1 & 3,2 & 1,5 & & 0,5 & \\
\hline
\end{tabular}

DAS = dias após a semeadura; Sinais "+" indicam semelhança entre o tratamento e a testemunha pelo teste de Dunnet $(p \leq 0,01)$.

Quando foram realizadas duas aplicações dos tratamentos herbicidas, observou-se níveis mais elevados de fitointoxicação. Na semeadura realizada no dia da segunda aplicação (B), ou 0 dias, todos os tratamentos herbicidas apresentaram fitointoxicação das plantas de milho. $O$ tratamento glyphosate + dicamba + saflufenacil ocasionou na morte das plantas de milho. Quando o milho foi semeado aos 30 dias, apenas as plantas presentes nas parcelas que receberam a aplicação sequencial dos tratamentos com 2,4D, 2,4-D + glyphosate e 2,4-D + saflufenacil apresentaram níveis de fitointoxicação baixos o suficiente para não diferir da testemunha sem aplicação.

Para o milho semeado aos 60 dias, as plantas presentes nas parcelas que receberam a aplicação sequencial de 2,4-D + [imazapic+imazapyr], 2,4-D + glyphosate + saflufenacil e glyphosate + saflufenacil + fluroxypyr também passaram a não diferir da testemunha sem herbicida. Os tratamentos 2,4-D + glyphosate + sulfentrazone, glyphosate + saflufenacil + [imazapic+imapyr] e fluroxypyr proporcionaram efeito residual longo no solo, ocasionando em fitointoxicação das plantas milho mesmo quando semeadas aos 90 dias. Não houve diferença significativa entre os tratamentos herbicidas e a testemunha sem aplicação apenas na semeadura realizada aos 120 dias.

Apesar do dicamba e do fluroxypyr serem herbicidas mimetizadores de auxinas, o efeito residual desses herbicidas foi significativamente superior ao 2,4-D. O 2,4-D apresenta persistência curta a média nos solos e sua atividade residual, no geral, não excede a quatro semanas em solos argilosos e clima quente (SILVA et al. 2007). Tanto o dicamba quanto o fluroxypyr apresentam particularidades químicas que podem implicar em maior persistência destes herbicidas na solução do solo em comparação ao 2,4-D, consequentemente, maior atividade residual (VILLAVERDE et al. 2008, RODRIGUES \& ALMEIDA 2018). Essas características podem ter colaborado para que fossem observadas injúrias nas plantas de milho semeadas em período superior a 60 dias após a aplicação de glyphosate + dicamba + saflufenacil, e de até 90 dias após a aplicação do herbicida fluroxypyr.

Os valores referentes à altura relativa das plantas de milho semeadas aos 0, 30, 60, 90 e 120 após a aplicação sequencial (A/B) dos tratamentos herbicidas estão apresentados na Tabela 9. 
Tabela 9. Altura relativa (porcentagem em relação à testemunha sem herbicida) das plantas de milho semeadas aos 0, 30, 60, 90 e 120 após duas aplicações sequenciais dos tratamentos herbicidas. Experimento 2.

Table 9. Relative height (relative percentage of a check without herbicide) of corn plants sown at 0, 30, 60, 90 and 120 after two sequential applications of herbicide treatments. Experiment 2.

\begin{tabular}{|c|c|c|c|c|c|c|c|c|c|c|}
\hline \multirow{2}{*}{ Tratamentos (Aplicação A/B) } & \multicolumn{10}{|c|}{ Altura relativa (\%) das plantas de milho aos 30 DAS } \\
\hline & 0 Dia & & $30 \mathrm{Dia}$ & & $60 \mathrm{Dic}$ & & $90 \mathrm{Dia}$ & & 120 Dia & \\
\hline $2,4-D$ & 98,6 & + & 95,8 & + & 97,2 & + & 95,7 & + & 98,8 & \\
\hline 2,4-D + glyphosate & 86,0 & - & 97,7 & + & 98,6 & + & 95,4 & + & 97,2 & + \\
\hline 2,4-D + saflufenacil & 83,0 & - & 98,8 & + & 99,5 & + & 97,8 & + & 100,0 & + \\
\hline 2,4-D + [imazapic+imazapyr] & 72,5 & - & 81,1 & - & 97,9 & + & 97,0 & + & 100,3 & + \\
\hline 2,4-D + glyphosate + saflufenacil & 62,1 & - & 81,3 & - & 97,8 & + & 97,8 & + & 97,0 & + \\
\hline 2,4-D + glyphosate + [imazapic+imazapyr] & 18,4 & - & 36,9 & - & 75,1 & - & 99,5 & + & 100,0 & + \\
\hline 2,4-D + glyphosate + saflufenacil + [imazapic+imazapyr] & 19,0 & - & 35,9 & - & 86,1 & - & 99,3 & + & 98,8 & + \\
\hline 2,4-D + glyphosate + sulfentrazone & 13,4 & - & 24,0 & - & 83,4 & - & 94,7 & + & 96,9 & + \\
\hline 2,4-D + sulfentrazone & 25,4 & - & 42,5 & - & 78,0 & - & 97,1 & + & 97,1 & + \\
\hline Glyphosa & 65,6 & - & 82,0 & - & 96,7 & + & 96,8 & + & 97,6 & + \\
\hline Glyphosate + [imazapic+imazapyr] + fluroxypyr & 42,6 & - & 74,2 & - & 88,2 & - & 96,5 & + & 96,6 & + \\
\hline Glyphosate + dicamba + saflufenacil & 0,0 & - & 17,1 & - & 89,3 & - & 96,3 & + & 97,7 & + \\
\hline Glyphosate + saflufenacil + [imazapic+imazapyr] & 27,7 & & 53,0 & & 79,2 & - & 98,2 & + & 97,3 & + \\
\hline Fluroxypyr & 23,9 & - & 46,7 & - & 83,0 & - & 96,1 & + & 97,9 & + \\
\hline Testemunha sem aplicação & 100,0 & + & 100,0 & + & 100,0 & + & 100,0 & + & 100,0 & + \\
\hline $\mathrm{CV} \%$ & 6,0 & & 5,1 & & 3,2 & & 3,4 & & 2,9 & \\
\hline DMS & 6,1 & & 6,8 & & 6,1 & & 6,9 & & 6,0 & \\
\hline
\end{tabular}

DAS = dias após a semeadura; Sinais “+" indicam semelhança entre o tratamento e a testemunha pelo teste de Dunnet $(p \leq 0,01)$.

Os tratamentos 2,4-D + glyphosate e 2,4-D + saflufenacil apresentaram menor efeito residual e não se diferiram da testemunha sem aplicação quando avaliada a altura das plantas de milho semeadas aos 30 dias. Para a semeadura realizada aos 60 dias, outros três tratamentos (2,4-D + [imazapic+imazapyr], 2,4-D + glyphosate + saflufenacil e glyphosate + saflufenacil + fluroxypyr) também não apresentaram mais efeitos significativos no crescimento do milho. Os tratamentos herbicidas que apresentaram maior persistência (2,4D + glyphosate + [imazapic+imazapyr], 2,4-D + glyphosate + saflufenacil + [imazapic+imazapyr], 2,4-D + glyphosate + sulfentrazone, 2,4-D + sulfentrazone, glyphosate + [imazapic+imazapyr] + fluroxypyr, glyphosate + dicamba + saflufenacil, glyphosate + saflufenacil + [imazapic+imazapyr] e fluroxypyr) resultaram em menor desenvolvimento das plantas de milho em comparação a testemunha até 60 dias após a aplicação. Não houve efeito sobre o crescimento das plantas de milho semeadas a partir de 90 dias.

A aplicação sequencial de 2,4-D não afetou a altura das plantas de milho em nenhuma das épocas de semeadura. GOMES et al. (2017) observaram redução na altura das plantas de milho apenas com a aplicação de doses mais elevadas de 2,4-D (1800 g e.a. ha $\left.{ }^{-1}\right)$ até 5 dias antes da semeadura. Resultados semelhantes foram obtidos por REIS et al. (2010) aplicando $2010 \mathrm{~g}$ e.a. ha $^{-1}$ no dia da semeadura do milho.

O comportamento dos dados de massa seca relativa das plantas de milho nas semeaduras realizadas após a segunda aplicação sequencial se assemelhou aos obtidos para altura relativa (Tabela 10).

A massa seca das plantas de milho foi afetada para as semeaduras até 90 dias. Apenas as plantas de milho tratadas com a aplicação sequencial de 2,4-D não diferiram das plantas presentes na testemunha. Na semeadura realizada aos 30 dias, os tratamentos 2,4-D + glyphosate e 2,4-D + saflufenacil passaram a apresentar massa seca das plantas de milho semelhantes à testemunha sem aplicação. $O$ mesmo foi observado para os tratamentos 2,4-D + [imazapic+imazapyr], 2,4-D + glyphosate + saflufenacil e glyphosate + saflufenacil + fluroxypyr, quando o milho foi semeado aos 60 dias.

Os tratamentos que apresentaram atividade residual suficiente para afetar a massa seca das plantas de milho por período mais longo foram 2,4-D + glyphosate + sulfentrazone, glyphosate + saflufenacil + [imazapic+imazapyr] e fluroxypyr, promovendo valores de massa seca inferiores aos valores da testemunha nas semeaduras realizadas até 90 dias. Na semeadura realizada aos 120 dias, os tratamentos herbicidas não afetaram mais a massa seca das plantas de milho.

Os valores de IS foram estimados para as aplicações sequenciais dos tratamentos herbicidas com base nos dados obtidos e nas tolerâncias máximas propostas neste trabalho (10\% de redução em relação à testemunha sem herbicida). As equações utilizadas nas regressões estão dispostas na Tabela 11, as curvas ajustadas estão apresentadas na Figura 2 e os valores de IS na Tabela 12. 
Tabela 10. Massa seca relativa (porcentagem em relação à testemunha sem herbicida) das plantas de milho semeadas aos 0, 30, 60, 90 e 120 dias após duas aplicações sequenciais dos tratamentos herbicidas. Experimento 2.

Table 10. Relative dry mass (relative percentage of a check without herbicide) of corn plants sown at 0,30 , 60, 90 and 120 days after two sequential applications of the herbicide treatments. Experiment 2.

\begin{tabular}{|c|c|c|c|c|c|c|c|}
\hline \multirow{2}{*}{ Tratamentos (Aplicação A/B) } & \multicolumn{7}{|c|}{ Massa seca relativa (\%) do milho aos 30 DAS } \\
\hline & 0 Dia & is $30 \mathrm{Di}$ & as $60 \mathrm{Di}$ & as $90 \mathrm{Di}$ & & $120 \mathrm{D}$ & \\
\hline $2,4-D$ & 98,3 & 97,1 & 98,6 & 100,0 & + & 99,3 & + \\
\hline 2,4-D + glyphosate & 83,8 & 97,3 & 99,0 & 99,7 & + & 100,5 & + \\
\hline 2,4-D + saflufenacil & 82,3 & 98,3 & 99,5 & 99,9 & + & 99,6 & + \\
\hline 2,4-D + [imazapic+imazapyr] & 67,7 & 81,1 & 99,8 & 99,6 & + & 100,6 & + \\
\hline 2,4-D + glyphosate + saflufenacil & 65,6 & 79,7 & 99,5 & 100,0 & + & 98,8 & + \\
\hline 2,4-D + glyphosate + [imazapic+imazapyr] & 31,3 & 46,0 & 84,5 & 99,9 & + & 99,6 & + \\
\hline 2,4-D + glyphosate + saflufenacil + [imazapic+imazapyr] & 50,1 & 68,6 & 92,8 & 100,0 & + & 99,0 & + \\
\hline 2,4-D + glyphosate + sulfentrazone & 27,2 & 46,4 & 81,9 & 94,4 & - & 97,7 & + \\
\hline 2,4-D + sulfentrazone & 49,8 & 60,5 & 85,2 & 99,1 & + & 97,7 & + \\
\hline Glyphosate + saflufenacil + fluroxypyr & 64,2 & 68,6 & 98,6 & 99,2 & + & 99,4 & + \\
\hline Glyphosate + [imazapic+imazapyr] + fluroxypyr & 63,8 & 74,5 & 86,0 & 99,9 & + & 99,6 & + \\
\hline Glyphosate + dicamba + saflufenacil & 0,0 & 46,4 & 89,3 & 99,2 & + & 98,4 & + \\
\hline Glyphosate + saflufenacil + [imazapic+imazapyr] & 38,2 & 50,7 & 71,3 & 95,3 & - & 99,0 & + \\
\hline Fluroxypyr & 38,2 & 55,6 & 85,5 & 95,2 & - & 99,0 & + \\
\hline Testemunha sem aplicação & 100,0 & $+100,0$ & $+100,0$ & 100,0 & + & 100,0 & + \\
\hline $\mathrm{CV} \%$ & 5,6 & 4,9 & 2,6 & 2,0 & & 2,4 & \\
\hline DMS & 6,7 & 7,3 & 5,0 & 4,2 & & 5,0 & \\
\hline
\end{tabular}

DAS = dias após a semeadura; Sinais “+" indicam semelhança entre o tratamento e a testemunha pelo teste de Dunnet (p $\leq 0,01)$.

Tabela 11. Equações ajustadas para estimar o Intervalo de Segurança visando à semeadura do milho após a aplicação sequencial de herbicidas no controle de soqueiras do algodoeiro. Experimento 2.

Table 11. Equations adjusted to estimate the safety interval for maize sowing after the sequential application of herbicides in the cotton stalks control. Experiment 2.

\begin{tabular}{|c|c|c|c|}
\hline Tratamentos & Fitointoxicação & Altura relativa & Matéria seca relativa \\
\hline $2,4-D$ & $\hat{y}=23.00^{*} E X P\left(-0.07^{*} x\right)$ & - & $\begin{array}{l}\hat{P}=97.78+(1.90 /(1+E X P(- \\
(x-60.38) / 1.60)))\end{array}$ \\
\hline 2,4-D + glyphosate & $\bar{P}=16.50^{*} E X P\left(-0.06^{*} x\right)$ & - & $\begin{array}{l}\hat{Y}=99.98 /(1+E X P(- \\
(x+26.06) / 15.82))\end{array}$ \\
\hline 2,4-D + saflufenacil & $\hat{y}=14.75^{\star} E X P\left(-0.06^{\star} x\right)$ & $\begin{array}{l}\dot{y}=99.46 /(1+E X P(- \\
(x+14.15) / 8.74))\end{array}$ & $\begin{array}{l}\hat{Y}=99.77 /(1+E X P(- \\
(x+17.61) / 11.31))\end{array}$ \\
\hline $\begin{array}{l}\text { 2,4-D + } \\
\text { [imazapic+imazapyr] }\end{array}$ & $\tilde{Y}=36.75 /\left(1+\left((x / 32.76)^{\wedge} 5.50\right)\right)$ & $\begin{array}{l}\hat{F}=72.28+(26.43 /(1+E X P(- \\
(x-34.99) / 7.26))\end{array}$ & $\begin{array}{l}\hat{y}=103.49 /(1+E X P(- \\
(x+19.15) / 32.31))\end{array}$ \\
\hline $\begin{array}{l}2,4-D+\text { glyphosate }+ \\
\text { saflufenacil }\end{array}$ & $\ddot{z}=38.24 /\left(1+\left((x / 39.60)^{\wedge} 6.43\right)\right)$ & $\begin{array}{l}\hat{y}=99.40 /(1+E X P(- \\
(x+12.06) / 24.95))\end{array}$ & $\begin{array}{l}\hat{y}=102.44 /(1+E X P(- \\
(x+15.92) / 30.30))\end{array}$ \\
\hline $\begin{array}{l}\text { 2,4-D + glyphosate } \\
+[\text { imazapic+imazapyr }]\end{array}$ & $\begin{array}{l}\hat{f}=- \\
11.14+\left(93.77 /\left(1+\left((x / 41.87)^{\wedge} 2.14\right)\right)\right)\end{array}$ & $\begin{array}{l}y=105.75 /(1+E X P(-(x- \\
40.60) / 21.92))\end{array}$ & $\begin{array}{l}\hat{Y}=106.90 /(1+E X P(-(x- \\
30.03) / 26.74))\end{array}$ \\
\hline $\begin{array}{l}2,4-\mathrm{D}+\text { glyphosate + } \\
\text { saflufenacil + }\end{array}$ & $\begin{array}{l}\hat{y}=- \\
11.07+\left(75.98 /\left(1+\left((x / 42.70)^{\wedge} 1.91\right)\right)\right.\end{array}$ & $\begin{array}{l}\hat{y}=17.78+(81.70 /(1+E X P(- \\
(x-42.99) / 10.33))\end{array}$ & $\begin{array}{l}\hat{Y}=103.95 /(1+E X P(-(x- \\
4.22) / 30.50))\end{array}$ \\
\hline $\begin{array}{l}2,4-D+\text { glyphosate + } \\
\text { sulfentrazone }\end{array}$ & $\begin{array}{l}\hat{Y}=- \\
35.07+\left(111.87 /\left(1+\left((x / 74.80)^{\wedge} 1.70\right)\right)\right.\end{array}$ & $\begin{array}{l}\hat{y}=97.36 /(1+E X P(-(x- \\
41.18) / 11.76))\end{array}$ & $\begin{array}{l}\hat{y}=102.26 /(1+E X P(-(x- \\
29.84) / 25.13))\end{array}$ \\
\hline 2,4-D + sulfentrazone & $\begin{array}{l}\hat{y}=- \\
5.88+70.82 /\left(1+\left((x / 39.33)^{\wedge} 2.43\right)\right)\end{array}$ & $\begin{array}{l}\hat{y}=103.74 /(1+E X P(-(x- \\
34.16) / 25.21))\end{array}$ & $\begin{array}{l}\hat{y}=108.18 /(1+E X P(-(x- \\
10.99) / 40.79))\end{array}$ \\
\hline $\begin{array}{l}\text { Glyphosate + saflufenacil } \\
+ \text { fluroxypyr }\end{array}$ & $\hat{y}=50.99 /\left(1+\left((x / 22.60)^{\wedge} 3.79\right)\right)$ & $\begin{array}{l}\hat{y}=99.32 /(1+E X P(- \\
(x+17.88) / 27.82))\end{array}$ & $\begin{array}{l}\bar{Y}=106.89 /(1+E X P(- \\
(x+11.60) / 41.82))\end{array}$ \\
\hline $\begin{array}{l}\text { Glyphosate + } \\
\text { [imazapic+imazapyr] + } \\
\text { fluroxypyr }\end{array}$ & $\begin{array}{l}\hat{y}=- \\
5.62+\left(57.40 /\left(1+\left((x / 49.26)^{\wedge} 2.84\right)\right)\right)\end{array}$ & $\begin{array}{l}\hat{y}=97.38 /(1+E X P(-(x- \\
5.26) / 22.12))\end{array}$ & $\begin{array}{l}\hat{y}=112.45 /(1+E X P(- \\
(x+14.06) / 59.38))\end{array}$ \\
\hline $\begin{array}{l}\text { Glyphosate + dicamba + } \\
\text { saflufenacil } \\
\text { Glyphosate + saflufenacil } \\
+ \text { [imazapic+imazapyr] }\end{array}$ & $\begin{array}{l}\hat{y}=- \\
4.99+\left(104.79 /\left(1+\left((x / 44.97)^{\wedge} 3.39\right)\right)\right. \\
\hat{y}=- \\
24.48+\left(86.61 /\left(1+\left((x / 59.37)^{\wedge} 1.46\right)\right)\right)\end{array}$ & $\begin{array}{l}\hat{y}=97.11 /(1+E X P(-(x- \\
41.62) / 7.53)) \\
\hat{y}=102.74 /(1+E X P(-(x- \\
27.20) / 25.88))\end{array}$ & $\begin{array}{l}\hat{y}=97.71 /(1+E X P(-(x- \\
31.49) / 9.91)) \\
\hat{y}=118.38 /(1+E X P(-(x- \\
38.15) / 45.13))\end{array}$ \\
\hline Fluroxypyr & $\tilde{y}=67.43 /\left(1+\left((x / 35.36)^{\wedge} 2.84\right)\right)$ & $\begin{array}{l}\hat{y}=101.67 /(1+E X P(-(x- \\
30.23) / 22.42))\end{array}$ & $\begin{array}{l}\hat{y}=104.65 /(1+E X P(-(x- \\
20.27) / 31.05))\end{array}$ \\
\hline $\begin{array}{l}\text { Testemunha sem } \\
\text { aplicação }\end{array}$ & - & $\begin{array}{llll} & \end{array}$ & - \\
\hline
\end{tabular}

aplicação

(-) não ajustada. Em que: ${ }^{\ddot{E}}=$ altura, biomassa e/ou fitointoxicação; $x=$ dias após a semeadura. 
a)

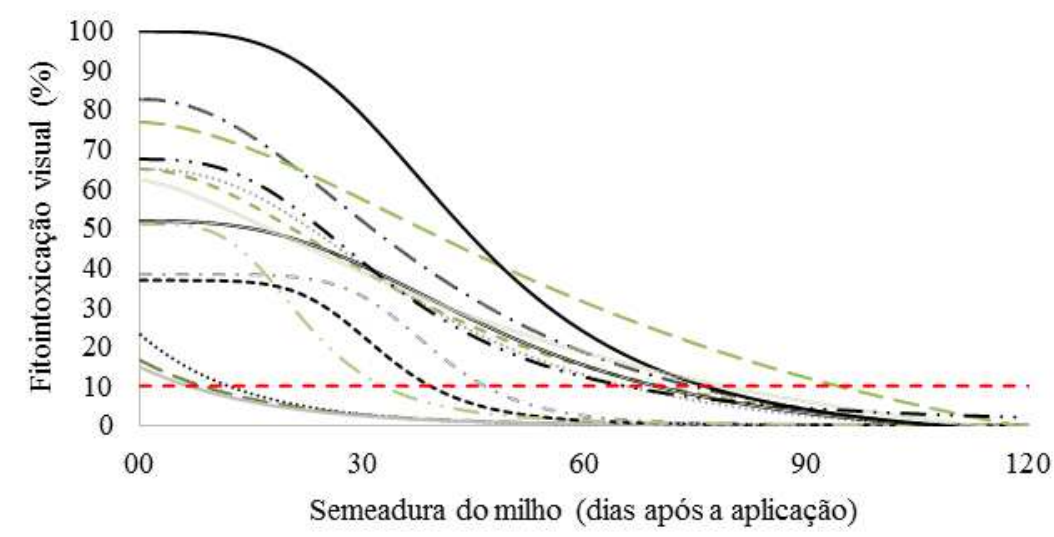

b)

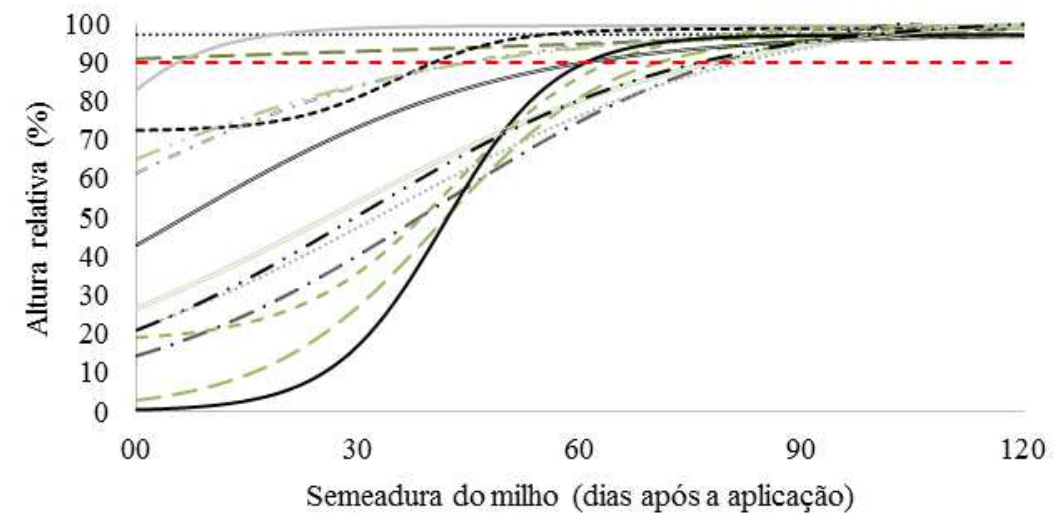

c)
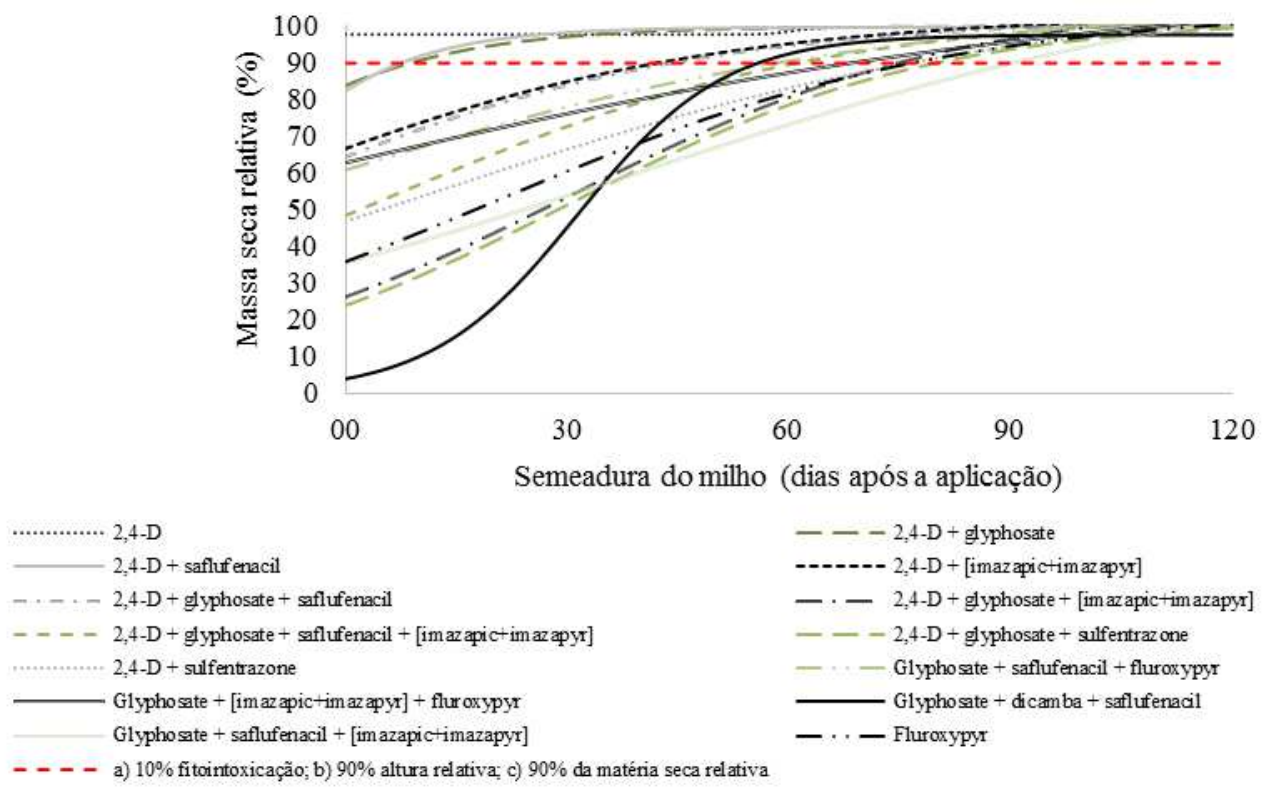

Figura 2. Fitointoxicação (a), altura relativa (b) e massa seca relativa (c) das plantas de milho semeadas aos 0, 30, 60, 90 e 120 dias após a aplicação sequencial dos tratamentos herbicidas utilizados no controle de soqueiras do algodoeiro. Experimento 2.

Figure 2. Phytotoxification (a), relative height (b) and relative dry mass (c) of corn plants sown at $0,30,60$, 90 and 120 days after the sequential application of herbicide treatments used to control cotton stalks. Experiment 2.

Os menores IS calculados foram de sete dias para a aplicação sequencial de 2,4-D + saflufenacil, de 8 dias para 2,4-D + glyphosate e de 11 dias para 2,4-D. Os maiores IS observados neste trabalho foram observados após aplicação sequencial de 2,4-D + glyphosate + sulfentrazone (94 dias), glyphosate + 
saflufenacil + [imazapic+imazapyr] (90 dias) e 2,4-D + sulfentrazone (81 dias). Estes períodos devem ser considerados se o objetivo for cultivar o milho em sucessão ao algodão.

Tabela 12. Intervalo de segurança estimado com base nos dados de fitointoxicação, altura relativa e massa seca relativa após duas aplicações sequenciais dos tratamentos herbicidas avaliados neste trabalho, visando a semeadura do milho. Experimento 2.

Table 12. Estimated safety interval based on phytotoxicity data, relative height and relative dry mass after two sequential applications of the herbicide treatments evaluated in this work, aiming corn sowing. Experiment 2.

\begin{tabular}{lccc}
\hline \multirow{2}{*}{\multicolumn{1}{c}{ Tratamentos (Aplicação A/B) }} & \multicolumn{3}{c}{$\begin{array}{c}\text { Intervalo de Segurança (IS) para o milho } \\
\text { (em dias após a aplicação) })^{1 /}\end{array}$} \\
\cline { 2 - 4 } & Fitointoxicação & Altura & Matéria seca \\
\hline 2,4-D & 11 & 0 & 0 \\
2,4-D + glyphosate & 7 & 0 & 8 \\
2,4-D + saflufenacil & 6 & 5 & 7 \\
2,4-D + [imazapic+imazapyr] & 39 & 40 & 42 \\
2,4-D + glyphosate + saflufenacil & 46 & 44 & 43 \\
2,4-D + glyphosate +[imazapic+imazapyr] & 74 & 78 & 74 \\
2,4-D + glyphosate + saflufenacil + [imazapic+imazapyr] & 70 & 64 & 61 \\
2,4-D + glyphosate + sulfentrazone & 94 & 70 & 79 \\
2,4-D + sulfentrazone & 66 & 81 & 76 \\
Glyphosate + saflufenacil + fluroxypyr & 32 & 45 & 57 \\
Glyphosate + [imazapic+imazapyr] + fluroxypyr & 69 & 60 & 68 \\
Glyphosate + dicamba + saflufenacil & 76 & 60 & 55 \\
Glyphosate + saflufenacil + [imazapic+imazapyr] & 78 & 77 & 90 \\
Fluroxypyr & 67 & 75 & 76 \\
Testemunha sem aplicação & - & - & -
\end{tabular}

11 Em negrito o maior valor estimado para IS, considerando as três variáveis-respostas avaliadas.

A presença de herbicidas com atividade residual nos tratamentos utilizados na destruição de soqueiras do algodoeiro, como é o caso do [imazapic+imazapyr] e sulfentrazone, também apresentaram potencial para afetar o milho semeado em sucessão. O imazapic e o imazapyr pertencem ao grupo químico das imidazolinonas e são caracterizados pela eficácia em baixas doses e pela longa persistência no solo, influenciada por propriedades como $\mathrm{pH}$, a umidade, o teor de matéria orgânica e, ainda, apresentam limitada biodegradação quando em condições anaeróbicas (RODRIGUES \& ALMEIDA 2018). Em solos com $\mathrm{pH}$ próximos a 4,7, estes herbicidas apresentam menor mobilidade no solo e maior persistência, o que pode afetar as plantas sensíveis até 210 dias após a aplicação, enquanto em pH 6,0 este efeito se dissipa no perfil do solo, ocorrendo uma lixiviação mais pronunciada do herbicida, reduzindo a persistência e afetando as plantas sensíveis em até 150 dias (MONQUERO et al. 2010).

O sulfentrazone, outro herbicida com atividade residual, apresenta longa persistência no solo, o que aumenta o risco de afetar as culturas em sucessão, como observado neste trabalho. Estima-se que a meiavida do sulfentrazone no solo seja entre 110 e 280 dias, variando de acordo com as condições edafoclimáticas locais (VIVIAN et al. 2006). Efeitos fitotóxicos da aplicação de sulfentrazone foram observados mesmo semeando o milho 60 dias após a aplicação (ARTUZI \& CONTIERO 2006). Este resultado obtido pelos autores corrobora com o observado neste trabalho, onde a aplicação de 2,4-D + sulfentrazone, com ou sem a adição de glyphosate, proporcionou fitointoxicação das plantas de milho semeadas até 60 dias quando realizada a aplicação única. Quando se realiza duas aplicações sequenciais dos tratamentos, foi observado um aumento na persistência destes herbicidas, podendo afetar as plantas de milho semeadas até 90 dias.

Os resultados obtidos neste trabalho podem ter superestimado o intervalo de segurança para alguns herbicidas. Isso se deve ao fato que a condução dos experimentos foi realizada em casa de vegetação, simulando uma possível condição que ocorre no campo. Ainda, entre a aplicação dos tratamentos e a semeadura do milho, os vasos não receberam nenhuma irrigação, o que pode resultar em uma degradação mais lenta dos herbicidas no solo. Desta forma, os resultados fornecem indicativos da atividade residual desses herbicidas que podem auxiliar na adoção de estratégias de manejo das soqueiras do algodoeiro em cumprimento ao período de vazio sanitário, visando o cultivo do milho na safra seguinte. 


\section{CONCLUSÃO}

Diante do exposto, conclui-se que a aplicação sequencial da maioria dos tratamentos proporcionou aumento no período de atividade residual dos herbicidas avaliados. A aplicação dos tratamentos 2,4-D, 2,4D + glyphosate e 2,4-D + saflufenacil, em aplicação única ou sequência, semeadura apresentou os menores intervalos de segurança (igual ou menor a 11 dias). Os tratamentos com dicamba, fluroxypyr, sulfentrazone ou [imazapic+imazapyr], apresentaram maior potencial de carryover para a cultura do milho, sendo observado intervalo de segurança de até 79 dias para aplicação única e de até 94 dias para a aplicação sequencial de 2,4-D + glyphosate + sulfentrazone.

\section{AGRADECIMENTOS}

O presente trabalho foi realizado com apoio do Conselho Nacional de Desenvolvimento Científico e Tecnológico (CNPq) e da Coordenação de Aperfeiçoamento de Pessoal de Nível Superior (CAPES) Código de Financiamento 001.

\section{REFERÊNCIAS}

ARTUZI JP \& CONTIERO RL. 2006. Herbicidas aplicados na soja e produtividade do milho em sucessão. Pesquisa Agropecuária Brasileira 41: 1119-1123.

BELTRÃO NEM. 2006. Fisiologia da produção do algodoeiro. Campina Grande: Embrapa Algodão. 8p. (Circular Técnica 94).

BIANCHINI A \& BORGES PHM. 2013. Evaluation of cotton stalks destroyers. Engenharia Agrícola 34: 965-975.

DAN HA et al. 2012. Resíduos de herbicidas utilizados na cultura da soja sobre o milho cultivado em sucessão. Caatinga 25: 86-91.

FRANCISCHINI AC et al. 2019. Associação de métodos mecânicos e químicos visando ao controle das soqueiras do algodoeiro. Planta Daninha 37: 1-9.

FREIRE EC. 2007. Algodão no Cerrado do Brasil. Brasília: Associação Brasileira dos Produtores de Algodão. 918p.

GOMES SA et al. 2017. Residual effect of mixture of glyphosate and 2,4-D in winter maize in different soil textures. Revista Brasileira de Engenharia Agrícola e Ambiental 21: 317-321.

GONÇALVES FAR et al. 2018. Atividade residual de herbicidas nas culturas do milho e da soja. Revista de Ciências Agrárias 61: 1-6.

IZEPPI TS et al. 2011. Ocorrência de Aphis gossypii (Hemiptera: Aphididae) e Cycloneda sanguinea (Coleoptera: Coccinelidae) em rebrota de plantas roçadas de cultivares comerciais de algodoeiro. Biológico 73: 314-317.

MARCHESAN ED et al. 2016. Integration mulches with atrazine for weed management in corn. Revista Brasileira de Ciências Agrárias 11: 1-7.

MATTE WD et al. 2018. Residual activity of [imazapic+imazapyr] applied to imidazolinones resistant soybean on cotton in succession. Planta Daninha 36: 1-9.

MATTE WD et al. 2019. Residual activity of diclosulam applied to soybean on cotton crop in succession. Planta Daninha $37: 1-8$

MONQUERO PA et al. 2010. Lixiviação e persistência dos herbicidas sulfentrazone e imazapic. Planta Daninha 28: 185195.

REIS TC et al. 2010. Efeitos de fitotoxidade do herbicida 2,4-D no milho em aplicações pré e pós-emergência. Revista de Biologia e Ciências da Terra 10: 25-33.

RIBEIRO EB et al. 2015. Métodos de destruição de restos de cultura do algodoeiro e sobrevivência do bicudo. Pesquisa Agropecuária Brasileira 50: 993-998.

RODRIGUES BN \& ALMEIDA FS. 2018. Guia de herbicidas. 7.ed. Londrina: Produção independente. 764p.

SILVA AA et al. 2007. Herbicidas: classificação e mecanismo de ação. In: SILVA AA \& SILVA JF (Eds.). Tópicos em manejo de plantas daninhas. Viçosa: UFV. p.83-148.

SILVA CAD \& RAMALHO FS. 2013. Kaolin spraying protects cotton plants against damages by boll weevil Anthonomus grandis Boheman (Coleoptera: Curculionidae). Journal of Pest Science 86: 563-569.

SILVA CAD et al. 2013. Recomendações técnicas para o manejo integrado de pragas do algodoeiro no Brasil. Campina Grande: Embrapa Algodão. 12p. (Circular técnica 135).

SOLTANI $N$ et al. 2011. The effect of residual corn herbicides on injury and yield of soybean seeded in the same season. Canadian Journal of Plant Science 91: 571-576.

VILLAVERDE $\mathrm{J}$ et al. 2008. Adsorption and degradation of four acidic herbicides in soils from Southern Spain. Pest Management Science 64: 703-710.

VIVIAN R et al. 2006. Persistência de sulfentrazone em Argissolo Vermelho-Amarelo cultivado com cana-de-açúcar. Planta Daninha 24: 741-750.

YANG C et al. 2006. Assessing cotton stalk destruction with herbicides using remote sensing technology. The Journal of Cotton Science 10: 136-145. 